\title{
Roadmapping implementation in digital startups: cases of study in agile environment
}

\author{
Ana Carolina dos Santos Paes ${ }^{a}$ (D), Aline Calamita Soares ${ }^{\circledR}$ D, Isadora Marques Lima ${ }^{a}$, \\ Leonel Del Rey de Melo Filho ${ }^{a}$, , Matheus Luiz Pontelo de Souza ${ }^{a}$ \\ - Departamento de Engenharia de Produção, Pontifícia Universidade Católica de Minas Gerais - PUC Minas, Belo Horizonte, MG, Brasil \\ e-mails: anacarolinads.paes@gmail.com; aline.calamita@gmail.com; isadoraamlima@gmail.com; leoneldr@pucminas.br; mslzposa@gmail.com
}

\begin{abstract}
Startups are conquering relevant space in the market. This way to make entrepreneurship has singular features, such as resource limitations and extreme uncertain environment. In this context, using auxiliary tools for managing the business and technology can be potentially helpful. There are many tools for managing product development in large companies. These tools are not immediately applicable when greater agility is required, as in startups. Thus, the purpose of this article is to analyze the use of roadmapping in the context of digital entrepreneurship and to describe factors that may be considered essential for the success or failure of implementation. The methodology in this paper was multiple cases of studies involving interviews with three entrepreneurs of different startups. After analyzing and comparing the data and contextualizing them in theory, four main factors affecting the use of roadmapping in startups were found: lack of theoretical knowledge, the specific moment of the startup in its life cycle, team involvement with roadmapping process and methods associated with roadmapping. These factors are debated, difficulties are shown and comments about method implementation are described.
\end{abstract}

Keywords: adaptation of methods, digital entrepreneurship, product development management, roadmapping, startup.

\section{Introduction}

Startups have become relevant among academics and professionals in many areas, as these ventures present specific conditions in their creation and in their economic impact. According to Ries (2011, p. 24), “[...] a startup is a human institution projected to create new products and services under conditions of extreme uncertainty". Estimates have shown that, in July 2018, there were approximately 62 thousand entrepreneurs and 6 thousand startups in Brazil, representing an increase of more than 50\% compared to the previous six years (Brito, 2018). Because of resource constraints and the risk of innovating, which are part of the business concept, startups face challenges to remain in the market and achieve significant growth (Meyer, 2012). These factors have shown that project management, resource allocation and decision-making need to be carried out competently (Souza et al., 2018).

Digital entrepreneurship (DE) may be defined as a process for creating digital startups either as a new business or a business within an established company (Zaheer et al., 2019). DE has gone through three phases, the third consisting of a combination of agile software development methods with strong experimentation and interaction processes. This phase broadened the study of classical topics in entrepreneurship by applying methods such as the lean startup (Zaheer et al., 2019). DE is currently in its fourth phase and growing relevance. DE demands welladapted methods, which traditional schools have failed to provide (Blank, 2013). So, there is an opportunity to adapt methods that can potentially support startup development. For example, methods typically used in fields like new product development and technology management (e.g. Roadmapping and Quality Function Deployment - QFD).

However, some of these methods have arisen within large companies. Roadmapping is an example and as such needs to be adjusted so that it may be applied to agile environments, considering that any method is a product of its context with its potential and limitations (Cheng, 2003). There is a growing initiative to adapt tools from other contexts into digital entrepreneurship, an example being QFD. This is a robust method (Bouchereau \& Rowlands, 2000) not adapted to DE if applied according to the context in which it was created; nevertheless, it has already been adapted to the context of DE (Armellini et al., 2017; Souza et al., 2017). On the Roadmapping side, some authors have developed ways to combine agility principles to roadmapping, thereby increasing its adaptability (Carlos et al., 2018; Souza, 2018). 
According to Carlos et al. (2018), most roadmapping users find it difficult to keep roadmaps updated, which results in failure of the method in situations that differ from typical implementations in midsized and major companies. Carvalho et al. (2013) have underlined the lack of evidence demonstrating successful implementation of roadmapping in small companies. Furthermore, studies that reported successful implementations of this process have flaws in their methods, casting doubt on their results. Factors limiting the use of roadmapping, therefore, remain neglected, which may affect future uses of this method.

To foster Roadmapping diffusion and adaptation to DE environment, the following case study aims to identify factors associated with success or failure of continued implementation of roadmapping in the context of digital entrepreneurship. A multiple case study was undertaken involving three information technology startups.

After analyzing and comparing the interviews and contextualizing them in theory, four main factors affecting the use of roadmapping in digital startups were found: i) lack of theoretical knowledge; ii) the specific moment of the startup in its life cycle; iii) team involvement with roadmapping; and iv) methods associated with roadmapping. These factors are debated, difficulties are shown and comments about implementation of the method are described.

\section{Review of the literature}

\subsection{Roadmapping}

Roadmapping is a product development management (PMD) method and technique, comprising the set of planning, organization and decision activities and tasks to attain successful results (Cheng \& Melo Filho, 2013).

According to those authors, roadmapping is defined as a flexible method to support PMD at a strategic level, aiming to integrate markets, products and technology over time. Phaal et al. (2004a) has stated that the method is unique because of its adaptability and flexibility.

According to Oliveira et al. (2012), roadmapping has been used successfully by large traditional companies to identify, define and map innovative strategies, objectives and actions. The tangible result of this process is a roadmap, a map that integrates and aligns different perspectives from several organizational areas and organizes information more clearly to explain the innovation context effectively. Phaal et al. (2010) has defined a roadmap as a structured visual framework, used to support the definition of innovation and strategy process, recognized by its potential to be integrated into other strategy and innovation tools.

One of the most iconic differences between roadmapping and other innovation management tools is the arrangement of axes in the roadmap - the result of the process - as shown in Figure 1. The " $x$ " axis is time and the " $y$ " axis is divided into

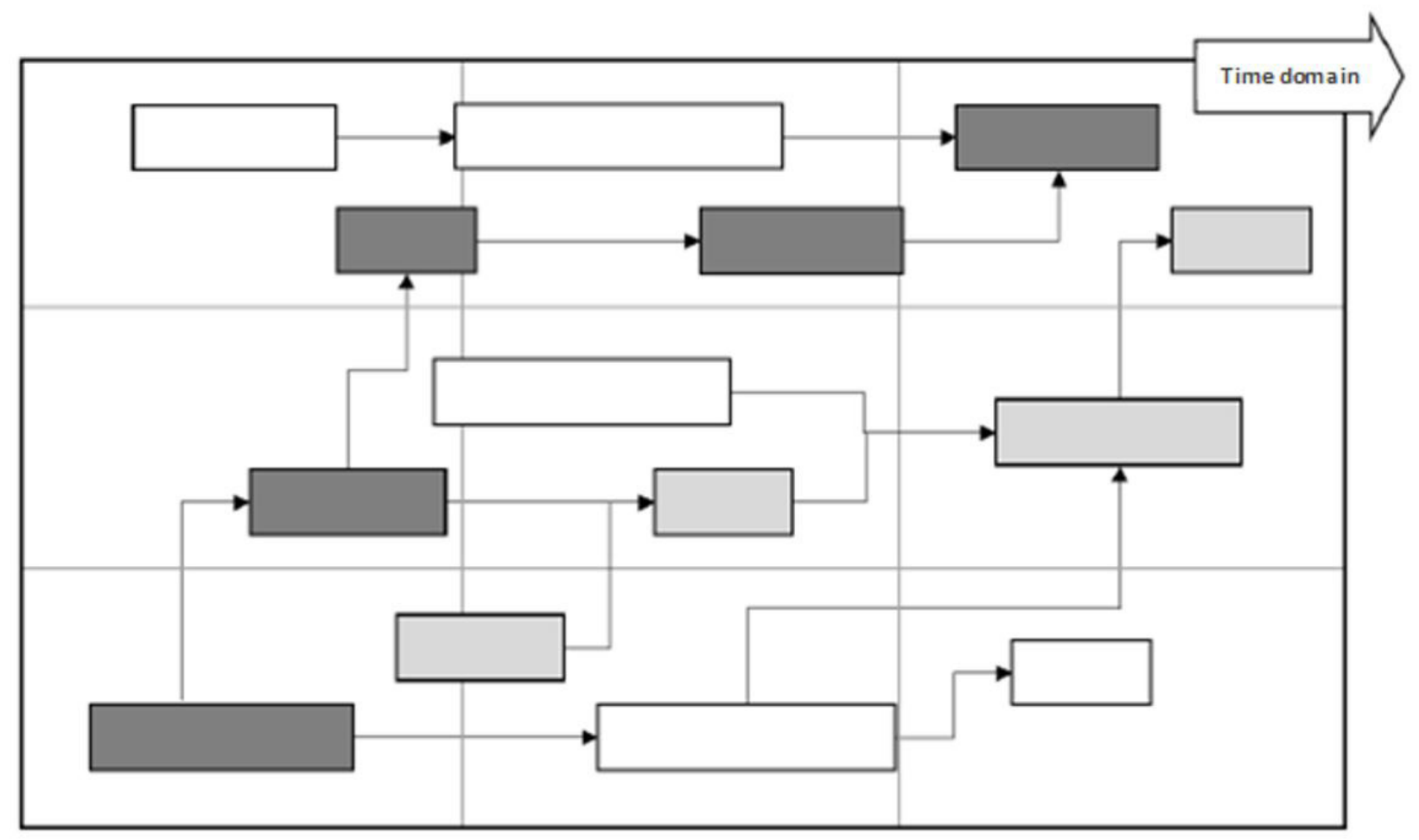

Figure 1. Roadmap example. Source: Oliveira et al. (2012, p. 9). 


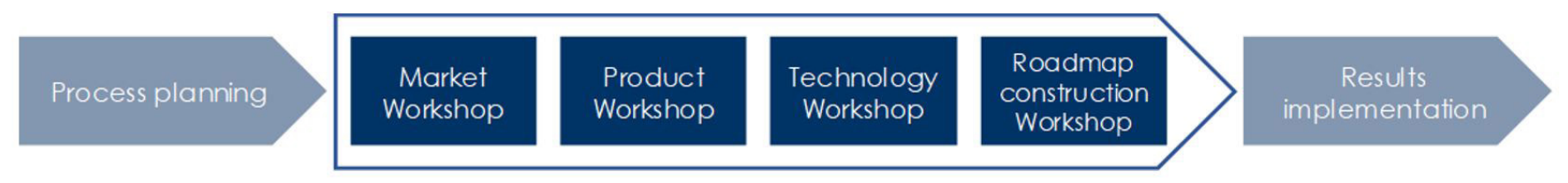

Figure 2. The T-Plan roadmapping process. Source: adapted by Oliveira et al. (2012).

layers according to the purpose of the application (Phaal \& Muller, 2009) such as market, products or technology layers.

According to Oliveira et al. (2012), the T-Plan is an approach to roadmapping. It may be a fast start to implement this method in organizations. The T-Plan process may be divided into four workshops (Figure 2), preceded by a plan. Customization during the planning phase may be required to adapt the method to a given organizational context: roadmap architecture questions, stakeholders, available resources, and other demands can be defined here. Four workshops (market, product, technology and roadmap construction) are then undertaken.

\subsection{Roadmapping in agile environments}

According to Phaal et al. (2004b, 2006), roadmapping has been used in a wide range of applications because of its graphic possibilities and the range of objectives to which it can be applied to support organizations.

Several roadmapping case studies have shown applications beyond traditional uses, as described by Souza (2018), such as its use with agile management methodology (SCRUM).

Carlos et al. (2018) have successfully proposed a continuous roadmapping update approach based on agile principles. Roadmapping, therefore, may be integrated into daily business process tasks to yield continuity in the method of an organization.

Some barriers and success factors can be mentioned in the implementation of roadmapping in digital startups. since the diffusion of the Agile Manifesto and the large recognition of the benefits from agile methods, the imperative of being "agile" spread over almost every innovation-related activity and field of research (Ries, 2017; Denning, 2018). This impacted directly in several fields and not only in the software industry, using the idea of hybrid models, which mix agile and traditional practices. According to Phaal et al. (2013) and Oliveira et al. (2012), the workshop approaches recommended in the application of roadmapping can consume many resources of digital startups. As an example, Kerr \& Phaal (2020) and Kerr et al. (2019) cite that the demand for structured workshops and support from external specialists, generally, demands many hours of work, which demands a lot of effort and resources for digital startups. As a result, the workshop approach is not yet adapted enough for digital startups in early stage. In addition, with the fast changes that digital startups have and the application of agile, many entrepreneurs do not usually get involved in processes that do not offer immediate learning. Carlos et al. (2018) and Gerdsri et al. (2009) mentions that becoming the roadmapping a continuous and living process in the organizational routine, instead of a stand-alone application, tends to be even harder for these organizations, due to the fact that roadmapping is a process that requires time and effort. Startups usually require practical methods to help the business development. Finally, roadmapping is a process that is usually done on a paper-based apparatus, which makes it difficult to update as many events (as in the case of agile environments) occur with greater speed (Lee \& Park, 2005). Therefore, the roadmapping application in these environments is still not widespread.

\section{Methodology}

\subsection{Case study}

Case studies may be applied to study variables that are not yet fully known and phenomena that are not completely understood. Their results may yield novel perspectives and generate relevant new theories (Voss et al., 2002). These authors have also pointed out that multiple case studies may be useful to reduce biases in specific features of single cases.

Following the purpose by Voss et al. (2002), as described above, the present study considered:

- Phenomenon: the implementation of roadmapping on digital startup;

- Variables: the limiting factors to this implementation;

- Results: factors that had influence on the success or failure of applying the method;

- Context: startups in the information technology sector.

A case study may be deemed an appropriate method for our purpose in this paper, given a lack of studies on the limiting factors of roadmapping implementations as well as sparse evidence demonstrating successful implementation and perpetuation of this process in small organizations.

Semi-structured interviews were carried out to gather data in three startups to understand how roadmapping was applied in their environment. Each interview lasted 
about 45 minutes and was done with those in charge of applying roadmapping, namely chief executive officers (CEOs) and chief technology officers (CTOs). The interviews were recorded using the ifree skype recorder ${ }^{\circledR}$ software and then transcribed to facilitate analysis.

To strengthen this case study, methodological features from Event Structure Analysis (ESA) (Heise \& Durig, 1997; Freitas, 2014) were used. First, the preparation of semi-structured questionnaires had a focus on obtaining verbs (events) from the respondents, highlighting both the temporal logics and the sequence agent $->$ event $->$ effect. Second, the analysis of data took careful attention to temporal logic and the chain of actions (verbs) through the narratives of success or failure of the implementation of Roadmapping efforts. Considering that an event on ESA analysis is represented by a verb on the interviewee's speech, it was possible to identify relevant events (actions, in other words) that led the study to the striking factors of roadmapping's application. For that, it was necessary to compare the three startups practice to the theory basis.

\section{Results and discussion}

\subsection{Contextualization of the cases}

The study was carried out with three digital startups, inserted in an agile environment, which brought interesting perspectives regarding roadmapping and its application.

Startup $\mathrm{S}$ is a technology startup, with a BusinessTo-Business (B2B) business model, whose product is a CRM system for complex sales control, monitoring, and management. Acting in the Software as a Service (SaaS) format, its development started in November 2015 and, in the first quarter of 2017, started as sales. Having studied and perceived value in the methodology while still in college, the CEO of Startup S applied the roadmapping in three different moments, with the implementation of the method only lasting for the third time.

Startup M has a Business to Consumer (B2C) business model. Created in 2016, in addition to being a channel for promoting third-party products, it offers a digital platform to offer personal stylist services in a democratic and accessible way. The CEO of startup M, even without knowledge of the methodology and time to dedicate to studying it better, tried to apply the roadmapping twice but failed in both attempts.

Operating in both B2B and Business-To-Business-ToConsumer (B2B2C), startup B's product is a platform, in the SaaS format, which can be considered a real estate marketplace. Like startup M, the CTO, responsible for implementing roadmapping, also had no knowledge of the methodology, was at a stage of many rapid changes, and was unsuccessful in attempting to apply roadmapping.

\subsection{Analysis of the questionnaire results}

Data analysis led to evaluations on a review of the literature. Considering the agile environment in which the three startups were in, four factors stood out in the interviews about the roadmapping's application: lack of theoretical knowledge, the specific moment of the startup in its life cycle, team involvement with roadmapping and methods associated with roadmapping.

The first factor, lack of theoretical knowledge, was revealed by the logic analysis. If the person has not studied the method, by logic he will not know the right steps to follow on the application, leading to the application failure. Also, it was clear from the "relevant events" analysis that only one interviewee (startup S's CEO) actually studied the method more profoundly.

By that, it was possible to consider the lack of knowledge a potential striking factor for the successful method's application.

The second factor is about the specific moment of the startup in its life cycle. Roadmapping is a process that requires time and effort, for example, holding structured workshops, supporting external specialists and involving people from different organizational functions and hierarchical levels, as approached by Oliveira et al. (2012). In additional to the high volume of uncertainty, information asymmetry, technical and managerial complexity in business development, limited resource and intense changes in a few months, characteristic of agile environments, in the initial stages, startups do not have a defined business model, they are still validating the product in the market, developing process with, generally, a lean team, making time an even scarcer resources (Ries, 2011). When startups reach more advanced stages, these problems diminish and, following a planning-based approach, such as roadmapping, can be critical in some cases.Considering these factors and the interviewees's experiences, it is observed that the roadmapping implementation in early life stages of startups has a great chance of being inefficient and flawed.

The third factor, team involvement with roadmapping, as approached by Oliveira et al. (2012), mentions that the main resource for roadmapping application is human, which includes the coordination team (process owner and the facilitators) and the execution team (people involved in the roadmapping development). The authors advise to include people from different areas in the organization to offer different perspectives on decision making. For digital startups, human resources are usually scarce due to the high level of uncertainties that these companies have and the scenario of intense changes every few months. In the interviews, the success of startup S's application was clearly influenced by the team involvement, as suggested by Oliveira et al. (2012). 
The fourth factor, methods associated with roadmapping, was approached by Carlos et al. (2018), as shown in 2.2. The three digital startups made the roadmapping integration to other methods. However, the two startups that had any previous knowledge of the roadmapping theoretical basis, did not succeed in applying it with other methods. Besides that, startup S's CEO, which studied the method more deeply, succeeded in associating roadmapping to other methods. Following that logic in the three cases analysis, it was possible to see the connection between two factors on the roadmapping application: the previous knowledge is relevant to associate roadmapping to other methods. This association, therefore, is essential considering the digital startups agile environment.

The four factors mentioned are described in greater detail below.

\subsubsection{Lack of theoretical knowledge}

Interviews revealed that prior knowledge of theory, especially the roadmapping implementation processes (besides the roadmap itself), increases the success rate of the method. Agile environments count with fast-changing and with very scarce resources, not only financial, but also human and time. That is why entrepreneurs focus their efforts on actions that generate immediate and evident results in their business. Although, the lack of such knowledge increases the chance of the method's implementation failure.

The CEO of startup M pointed out that poor knowledge about the method resulted from lack of time dedicated to study the roadmapping implementation. Two mentors of an acceleration process had arbitrarily chosen the method; they had not been able to demonstrate sufficient value to make roadmapping a priority for the CEO we interviewed. She understood it was just a requirement of the acceleration program. Thus, with no planning and in a single meeting, this CEO decided to apply the method by drawing the map without involving other team members. Such views emerge from the interviews: "In fact, I regret not having applied the method more thoroughly" and "my fault was not having studied roadmapping in depth."

A similar scenario emerged in the interview at startup B. Its CTO thought roadmapping was a bureaucratic method focused on documentation rather than a collective/visual strategy. He also thought that, in the context of the dynamic environment they worked in, roadmapping was a waste of time and "would reduce productivity by at least $30 \%$." This interview showed that the interviewee had only superficial knowledge about roadmapping theory and poor perception of the challenges he could really approach by using this approach.

The interview with the CEO of startup S revealed a different reality. He mentioned having studied roadmapping during his undergraduate course, became interested and had opportunities at the time to witness successful implementations of this method. He thus perceived its value in dealing with the challenges his startup faced. He perceived value in roadmapping such as the benefits of joint decision-making. There was also more commitment from those involved in the process which, according to this interviewee, made a difference compared to other planning tools in which only a single team member would propose team actions. He also stated that roadmapping helped with the "careful communication with investors" as he built the startup.

Meeting involving the entire team, workshops and method adaptations happened only as startup S, including generating a map in PowerPoint, using google drive to share information and integrating with SCRUM, which were done to "keep the method alive", according to the interviewee. Thus, prior knowledge of the method was important, as roadmapping was not discontinued and was subsequently used throughout the four years of the startup's existence.

\subsubsection{The specific moment of the startup in its life cycle}

At startup $S$, the interviewee argued that applying roadmapping in early stages of startup maturity was not the best option, given the scenario of intense changes every few months, characteristic of the agile environment in which the three analyzed startups are. He based this opinion on the fact that roadmapping application was tried three times in his startup, two of which in stages of lower corporate maturity. In these moments, roadmapping was discontinued because of fast startup growth, involving changes in strategy and the business model. The third time roadmapping was applied successfully, when the startup was more mature, with greater efficiency attained by connecting it with SCRUM (as will be described below). The interviewee gave a positive perspective of roadmapping.

At startup M, roadmapping was applied in two different moments, at a less mature step of the startup, which at the time was undergoing significant changes, mostly of its developing business model.

These initial trials were the basis of startup S's perception that roadmapping was less efficient when applied during early stages of startup development.

\subsubsection{Team involvement on the roadmapping implementation}

Startup M's interviewee considered roadmapping a good method if there was someone exclusively in charge of it. She also argued that branched roadmaps, rather than a general roadmap, made more sense in the context of their business strategy. This view emerged from unsuccessful implementations of roadmapping, even with support from 
the CTO. Workshops for implementing this method were not undertaken.

The CEO of startup S stated that success was achieved because he held prior meetings with investors, directors and commercial and product teams to align expectations, to set goals jointly and to detail these goals in roadmap layers. This CEO argues that the key point for maintaining roadmapping was adopting a roadmapping management routine involving all team members along the checkpoints of the acceleration program and thereafter every fifteen days.

The CTO of startup B oversaw roadmapping. He held weekly meetings for problem-solving, although such meetings varied according to demand. During the interview, this CTO described the strategy map, which he understood as being roadmapping, as an approach to deal with specific needs, rather than long-term planning. Thus, he interpreted the roadmapping as nothing more than a list of tasks. Although the participant was sure about the roadmapping use, it was clear in his interview that actually he did not understand the method concept. Therefore, the method's application didn't exist at first.

Digital startups are subject to many changes and often fail to have a well defined routine in their daily lives. This occurs due to the environment in which they are, which requires fast changes and an agile routine to develop. This agility requires big demand for the entire time, making human resources scarce. The team needs to comply with the backlog order of priority. Tasks with immediate results that have a direct influence on the startup's survival end up being a priority. Therefore, the method application such as roadmapping, which requires time, efforts, routine and study, may not include all team members. Thus, observing the cases studied, if there is no person dedicated to the application of the method, the implementation of roadmapping is compromised, given that it does not fit with the agile routine demanded by the digital startup team.

\subsubsection{Methods associated to roadmapping}

The interviewee of startup $\mathrm{M}$ stated that no adaptations were made to roadmapping, which was applied in its classical format. During the interview, it became clear that roadmapping was associated with the buyer's journey, given the company's focus on developing its sales funnel. Furthermore, roadmapping was associated with financial data to understand customer acquisition costs.

Startup S approached roadmapping efficiently. Hurdles against continuous implementation of the method resulted from difficulties in running workshops in the context of the company. Team members chose to study the method's integration to other tools to adapt the implementation to the startup's reality. SCRUM was used with roadmapping, which increased applicability and adherence to the routines. The startup's CEO also detailed the progress of the roadmapping process during its implementation, where efficiency increased as the process adapted and because of its connection with SCRUM. In this case, more accuracy was gained from roadmapping.

As mentioned above in the topic startup structure, there was no evidence that the CTO of startup B applied roadmapping, although mentioned otherwise. He undertook product development by using a strategic map detailed in cards of the Trello app rather than following the classical or adapted roadmapping structure. Kanban was also used continuously and was associated indirectly with tasks on the strategic map.

Due to the agile environment of startups, the application of roadmapping associated with the other agile methods or that are part of the company's routine can contribute to the continuous application of the method. This association between methods that are already known by digital startups can be fundamental for the roadmapping application in these companies.

\subsection{Discussion of results}

Lack of theoretical knowledge about roadmapping was a relevant factor for discontinuing it in startups $\mathrm{M}$ and $\mathrm{B}$ and for not perceiving its value. On the other hand, startup S's interviewee had knowledge about the theoretical underpinnings of roadmapping and understood the organizational challenges which roadmapping could potentially address. This perspective was a key factor for successful implementation of roadmapping at this company.

A common opinion emerged with regards to the specific moment of the startup in its life cycle. The three interviewees reported that roadmapping was not efficient when applied in the early phases of startups because of the highly variable conditions in such phases. With startups undergoing several changes and having urgent demands inherent in the initial phase, the application of roadmapping as the literature exposes is difficult to be applied by the entrepreneurs. As a result, they comment on the challenge of applying roadmapping that is reliable and simple in a startup.

A digital startup's maturity level may be an important factor when planning to implement roadmapping. A conflict, however, was seen; on the one hand, investors and accelerators demand methods such as roadmapping in early stage startups as was the case with startups $\mathrm{S}$ and $\mathrm{M}$, while on the other hand, entrepreneurs realized that its implementation during those early stages was inefficient.

Team involvement was also relevant for implementing roadmapping. In all three cases, strategic members were in charge of implementing roadmapping. However, effective team involvement was only possible in startup S. In startups $\mathrm{M}$ and $\mathrm{B}$, team involvement was poor, which negatively affected roadmapping implementation. 
The roadmapping method was adapted locally only at startup S, underlining the importance of this choice. In the three digital startups, roadmapping was associated with other tools already present in their daily routines, highlighting the still unexplored potential for applying roadmapping as a structuring framework for other management tools (Freitas et al., 2017).

\section{Conclusion}

The analysis of three cases to understand factors affecting implementation of roadmapping revealed four main factors: lack of theoretical knowledge, the specific moment of the startup in its life cycle, team involvement with roadmapping and methods associated with roadmapping.

Factors that led to failed implementation of roadmapping, as perceived in startups $\mathrm{M}$ and $\mathrm{B}$, have an underlying cause, namely poor knowledge of the method's theory. In these cases, inappropriate adaptation of the method resulted in not overcoming hurdles such as a lean structure or early startup stages. Thus, the challenge of applying roadmapping in digital startups is to provide a theory about roadmapping that is both reliable, simple, and fast, as entrepreneurs demand in agile environments. There are, however, difficulties in finding a description of theory that meets these requirements, which discourages widespread use of roadmapping in digital startups. Furthermore, most of the well-described descriptions of roadmapping theory are found in academic portals, which entrepreneurs generally ignore, making dissemination of this approach harder among digital entrepreneurship.

\section{References}

Armellini, F., Pelicioni, R. A., Kaminski, P. C., \& Bassetto, S. (2017). Including the voice of the client in the creative process: a case study of the integration of Quality Function Deployment (QFD) to the Value Proposition Design (VPD) in the service sector. The Journal of Modern Project Management, 5(2)

Blank, S. (2013). Why the lean start-up changes everything. Harvard Business Review, 91(5), 63-72.

Bouchereau, V., \& Rowlands, H. (2000). Methods and techniques to help Quality Function Deployment (QFD). Benchmarking, 7(1), 8-20.

Brito, D. (2018, July). Startups crescem no Brasil e consolidam nova geração de empreendedores. Agência Brasil. Retrieved in 2019, March 18, from http://agenciabrasil.ebc.com.br/ economia/noticia/2018-07/startups-crescem-no-brasil-econsolidam-nova-geracao-de-empreendedores

Carlos, R., Amaral, D. C., \& Caetano, M. (2018). Framework for continuous agile technology roadmap updating. Innovation \& Management Review, 15(3), 321-336.
Carvalho, M. M., Fleury, A., \& Lopes, A. P. (2013). An overview of the literature on technology roadmapping (TRM): contributions and trends. Technological Forecasting and Social Change, 80(7), 1418-1437.

Cheng, L. C. (2003). QFD in product development: methodological characteristics and a guide for intervention. International Journal of Quality \& Reliability Management, 20(1), 107-112.

Cheng, L. C., \& Melo Filho, L. (2013). QFD: desdobramento da função qualidade na gestão de desenvolvimento de produtos. São Paulo: Blücher.

Denning, S. (2018). The age of agile: how smart companies are transforming the way work gets done. New York: AMACOM.

Freitas, J. S. (2014). Eventos críticos para a formação de centros tecnológicos de origem acadêmica [Doctoral Dissertation]. Centro de Pós-graduação e Pesquisas em Administração, Universidade Federal de Minas Gerais, Belo Horizonte.

Freitas, J., Mudrik, J., Melo, J., Bagno, R., \& Oliveira, M. (2017). On the combination of strategy and innovation tools with roadmapping: exploring taxonomies and sequences. In Proceedings of the 26th International Association for Management of Technology Conference (IAMOT); 2017; Vienna. Vienna: IAMOT; 2017. p. 578-592.

Gerdsri, N., Vatananan, R. S., \& Dansamasatid, S. (2009). Dealing with the dynamics of technology roadmapping implementation: a case study. Technological Forecasting and Social Change, 76(1), 50-60.

Heise, D. R., \& Durig, A. (1997). A frame for organizational actions and macroactions. The Journal of Mathematical Sociology, 22(2), 95-123.

Kerr, C., \& Phaal, R. (2020). Technology roadmapping: industrial roots, forgotten history and unknown origins. Technological Forecasting and Social Change, 155, 119967.

Kerr, C., Phaal, R., \& Thams, K. (2019). Customising and deploying roadmapping in an organisational setting: the LEGO Group experience. Journal of Engineering and Technology Management, 52, 48-60.

Lee, S., \& Park, Y. (2005). Customization of technology roadmaps according to roadmapping purposes: overall process and detailed modules. Technological Forecasting and Social Change, 72(5), 567-583.

Meyer, J. (2012). Welcome to entrepreneur country. London: Hachette UK.

Oliveira, M., Freitas, J., Fleury, A., Rozenfeld, H., Phaal, R., Probert, D., \& Cheng, L. (2012). Roadmapping: uma abordagem estratégica para o gerenciamento da inovação em produtos, serviços e tecnologias. Rio de Janeiro: Elsevier. 
Phaal, R., \& Muller, G. (2009). An architectural framework for roadmapping: towards visual strategy. Technological Forecasting and Social Change, 76(1), 39-49.

Phaal, R., Farrukh, C. J., \& Probert, D. R. (2004b). Technology roadmapping: a planning framework for evolution and revolution. Technological Forecasting and Social Change, $71(1-2), 5-26$.

Phaal, R., Farrukh, C. J., \& Probert, D. R. (2010). Roadmapping for strategy and innovation: aligning technology and markets in a dynamic world. Cambridge: Institute for Manufacturing, University of Cambridge.

Phaal, R., Farrukh, C., \& Probert, D. (2004a). Customizing roadmapping. Research Technology Management, 47(2), 26-37.

Phaal, R., Farrukh, C., \& Probert, D. (2006). Technology management tools: generalization, integration and configuration. International Journal of Innovation and Technology Management, 3(03), 321-339.

Phaal, R., Farrukh, C., \& Probert, D. R. (2013). Fast-start roadmapping workshop approaches. In M. Moehrle, R. Isenmann \& R. Phaal (Eds.), Technology roadmapping for strategy and innovation (pp. 91-106). Berlin: Springer.

Ries, E. (2011). The lean startup: how today's entrepreneurs use continuous innovation to create radically successful businesses. New York: Crown Publishing.
Ries, E. (2017). The startup way: how modern companies use entrepreneurial management to transform culture and drive long-term growth. New York: Currency.

Souza, M. L. P. (2018). Empreendedorismo tecnológico: processo de geração de startups (p-start) e métodos de suporte ao reconhecimento, criação e exploração de oportunidades [Master's Thesis]. Instituto de Ciências Biológicas, Universidade Federal de Minas Gerais, Belo Horizonte.

Souza, M. L. P., Melo Filho, L. D. R., Oliveira, C. G. G., Aniceto, M. D., \& Silveira, C. A. (2017). Aplicação conjunta de métodos no desenvolvimento de startups: descrição e análise crítica. In Anais do Congresso Brasileiro de Inovação e Gestão de Desenvolvimento do Produto $(C B G D P)$ (pp. 725-734). São Paulo: USP.

Souza, M. L., Melo Filho, L. D., Bagno, R. B., Souza, W. C., \& Cheng, L. C. (2018, August). A process model integrated to innovation management tools to support technology entrepreneurship. In 2018 Portland International Conference on Management of Engineering and Technology (PICMET) (pp. 1-12). Piscataway: IEEE.

Voss, C., Tsikriktsis, N., \& Frohlich, M. (2002). Case research in operations management. International Journal of Operations \& Production Management, 22(2), 195-219.

Zaheer, H., Breyer, Y., \& Dumay, J. (2019). Digital entrepreneurship: an interdisciplinary structured literature review and research agenda. Technological Forecasting and Social Change, 148, 119735. 